\title{
Assessing flow regime alterations in a temporary river - the River Celone case study
}

\author{
Anna Maria De Girolamo ${ }^{1 *}$, Antonio Lo Porto ${ }^{1}$, Giuseppe Pappagallo ${ }^{1}$, Francesc Gallart ${ }^{2}$ \\ ${ }^{1}$ Water Research Institute, National Research Council, Francesco De Blasio 5, 70132 Bari, Italy. \\ ${ }^{2}$ Institute of Environmental Assessment and Water Research, Spanish National Research Council, Jordi Girona 18, 08034 Barcelona, \\ Spain. \\ * Corresponding author. Tel.: +390805820547. Fax: +390805313365. E-mail: annamaria.degirolamo@ba.irsa.cnr.it
}

\begin{abstract}
In this paper, we present an approach to evaluate the hydrological alterations of a temporary river. In these rivers, it is expected that anthropogenic pressures largely modify low-flow components of the flow regime with consequences for aquatic habitat and diversity in invertebrate species. First, by using a simple hydrological index (IARI) river segments of the Celone stream (southern Italy) whose hydrological regime is significantly influenced by anthropogenic activities have been identified. Hydrological alteration has been further classified through the analysis of two metrics: the degree $\left(M_{f}\right)$ and the predictability of dry flow conditions $\left(S d_{6}\right)$. Measured streamflow data were used to calculate the metrics in present conditions (impacted). Given the lack of data from pristine conditions, simulated streamflow time series were used to calculate the metrics in reference conditions. The Soil and Water Assessment Tool (SWAT) model was used to estimate daily natural streamflow. Hydrological alterations associated with water abstractions, point discharges and the presence of a reservoir were assessed by comparing the metrics $\left(M_{f}, S d_{6}\right)$ before and after the impacts. The results show that the hydrological regime of the river segment located in the upper part of the basin is slightly altered, while the regime of the river segment downstream of the reservoir is heavily altered. This approach is intended for use with ecological metrics in defining the water quality status and in planning streamflow management activities.
\end{abstract}

Keywords: Natural hydrological regime; Temporary stream; Hydrological modelling; Indicators of hydrological alteration.

\section{INTRODUCTION}

In recent decades, the importance of natural hydrological regimes in maintaining the integrity of rivers has been widely recognized (Bunn and Arthington, 2002; Poff et al., 1997; Richter et al., 1996). Anthropogenic pressures, such as dams, point source discharges, surface water abstractions, and hydropower, may modify the natural regime of a river with a negative impact on water quality, biotic composition, structures and the functioning of aquatic and riparian ecosystems (Buffagni et al., 2009; Hering et al., 2003; Lake, 2007; Munnè and Prat, 2011; Zoppini et al., 2010).

The relevance of the hydrological regime is recognized by the Water Framework Directive (WFD) (EC, 2000), which explicitly defines the hydro-morphological aspects as quality elements that must be used for the assessment of ecological status/potential. However, as a determinant of ecological status, the hydro-morphological quality elements are fixed only at High Quality Status, while, for other status classes, the hydromorphological elements are required to have "conditions consistent with the achievement of the values specified for the biological quality elements" (CIS, 2003a). The hydrological regime of a water body is part of the hydro-morphological quality elements (Annex V, WFD).

Five components are generally used to describe the flow regime: magnitude of discharge (amount of water moving past a fixed location per time unit), frequency (refers to how often a flow above a given magnitude recurs over some specified time intervals), duration (period of time associated with a specific flow condition), timing (regularity with which flows of defined magnitude occur) and rate of change (refers to how quickly flow changes from one magnitude to another) (Poff et al., 1997). Modification in these flow components has cascading effects on the ecological integrity of rivers.
Several metrics (also called hydrological descriptors or indicators) have been developed for characterizing the patterns of river flow, and specific hydrological components, which have a direct or indirect influence on biological communities (e.g. Annual Minimum and Maximum 1, 3, 7, 30 and 90-day streamflows, Zero-flow days, etc.) (Poff, 1996). A general approach for hydrological alteration assessment is based on the analysis of these metrics, which are compared before and after a river has been altered by human activities (Richter et al., 1996). This methodology, as well as other methods (Fernández Yuste et al., 2012; Henriksen et al., 2006; Martínez Santa-María and Fernández Yuste, 2008) generally used to analyse the status variations within a system over time, or to compare an altered system to a reference system, are based on streamflow data, which are referred to as un-impacted and impacted conditions. The method is simple to implement when streamflow data have been measured at the same river section before and after the change in the hydrological regime. However, it could be difficult to apply in several countries of the Mediterranean Basin where measured data availability is scarce, especially in pristine conditions (Oueslati et al., 2010). If observed flow data are not available, different approaches are used to generate flow series (Black et al., 2005). Hydrological models, such as HSPF, HEC-HMS, and the Soil and Water Assessment Tool (SWAT), can be used for long-term simulations of un-impacted or impacted conditions (Singh and Woolhiser, 2002). However, such models are parameter-intensive, they require a large amount of data to set up and calibrate the simulations (De Girolamo and Lo Porto, 2012). In addition, most of the hydrological models, which were developed for perennial rivers, present several limits in simulating extreme low-flow conditions in temporary rivers ${ }^{1}$ (De Girolamo et al., 2014; Kirkby et al., 2011). 
Although temporary rivers are quite common in the Mediterranean region, the basic principle of the Water Framework Directive has been developed mostly for perennial rivers (Nikolaidis et al., 2013). For temporary rivers, the ecological status assessment is more difficult to define and the management strategy to restore a good ecological status has to be quite specific. This has been recently pointed out by Prat et al. (2014) who proposed a new method, the so called "The MIRAGE tool box" for assessing hydrological, ecological and physicochemical aspects in temporary rivers.

In this context, the present paper describes a study which aims to (1) predict natural streamflow in a temporary river (Celone, Apulia in southern Italy) and (2) assess the hydrological alterations due to anthropogenic pressures. Two water bodies within a $70 \mathrm{~km}$ segment of the main course of the River Celone were identified where natural streamflow was predicted and hydrological alteration evaluated. The aim is to give water resource managers an easy tool which could facilitate any investigation into the effects of hydrological modifications within the biotic composition in temporary rivers.

\section{STUDY AREA}

We applied the proposed methodology to the River Celone, one of the most important tributaries of the River Candelaro, located in the Apulia region in southern Italy (Figure 1). The river flows northeast and enters the Capaccio reservoir (full capacity $25.82 \mathrm{Mm}^{3}$; current volume $17.56 \mathrm{Mm}^{3}$ ). The channel, which is incised in the upper basin, assumes a braided form in an alluvial plain downstream of the steeper reaches. Here, there is deposition of the coarser material before the river resumes a sinuous course. In the plain area, much of the river network appears as a series of concrete-lined channels. Hydraulic structures were built before World War I to artificially drain the area since the river network was unable to collect all the water from the large alluvial plain after storm events. The drainage area is
$317 \mathrm{~km}^{2}$ and the main river course is $93 \mathrm{~km}$ long. The soil texture varies from sandy-clay-loam (36\%) to sandy-clay $(1 \%)$ or clay $(63 \%)$. The basin is characterized by a mean elevation of about $300 \mathrm{~m}$, ranging from 0 to $1100 \mathrm{~m}$. The average annual precipitation evaluated with the Centroid method ${ }^{2}$ from 1990 to 2009 in the Celone River basin is $625 \mathrm{~mm}$, ranging from 465 $\mathrm{mm}$ in the plain area to $840 \mathrm{~mm}$ in the mountainous area. Rainfall is mostly concentrated in autumn and winter (from November to May). It is unevenly distributed throughout the region and during the dry season, from June to September, it is concentrated in a few events of short duration and high intensity. The main economic activity in the plain area is intensive agriculture, the main farming products being durum wheat (70\%), tomatoes $(3 \%)$, sugar beet $(6 \%)$, olives $(4 \%)$, and grapes $(3 \%)$. In the mountainous part of the basin, where the morphology is more irregular, natural and man-made, forest lands $(8 \%)$ and pasture $(2 \%)$ are frequent and agriculture is not intensive. The streamflow follows the precipitation regime closely. The river network shows an intermittent character, with a pattern of zero or low flow and the reduction of the surface water into isolated pools along the river during the summer months. From June to September flash flood events are quite common, flood duration is typically only a few hours with a very rapid rising stage and a short lag time (time between peak rainfall and peak discharge). In winter, after the discharge reaches its flow peak, it falls off gradually resulting in a very slow recession with a duration depending on the antecedent soil moisture, and on the intensity and time interval of the rainfall that produced it. From 1965 to 1995 , the average streamflow values were 0.48 and $0.77 \mathrm{~m}^{3} \mathrm{~s}^{-1}$ at streamflow gauge 1 and 2, respectively. In Italy, awareness of the importance of environmental monitoring is increasing. A new streamflow monitoring plan was recently designed and Civil Protection Service is in charge of measurements. However, due to the limited economic resources not all water bodies are well monitored yet and currently no streamflow data are available for all the water bodies identified in the study area.

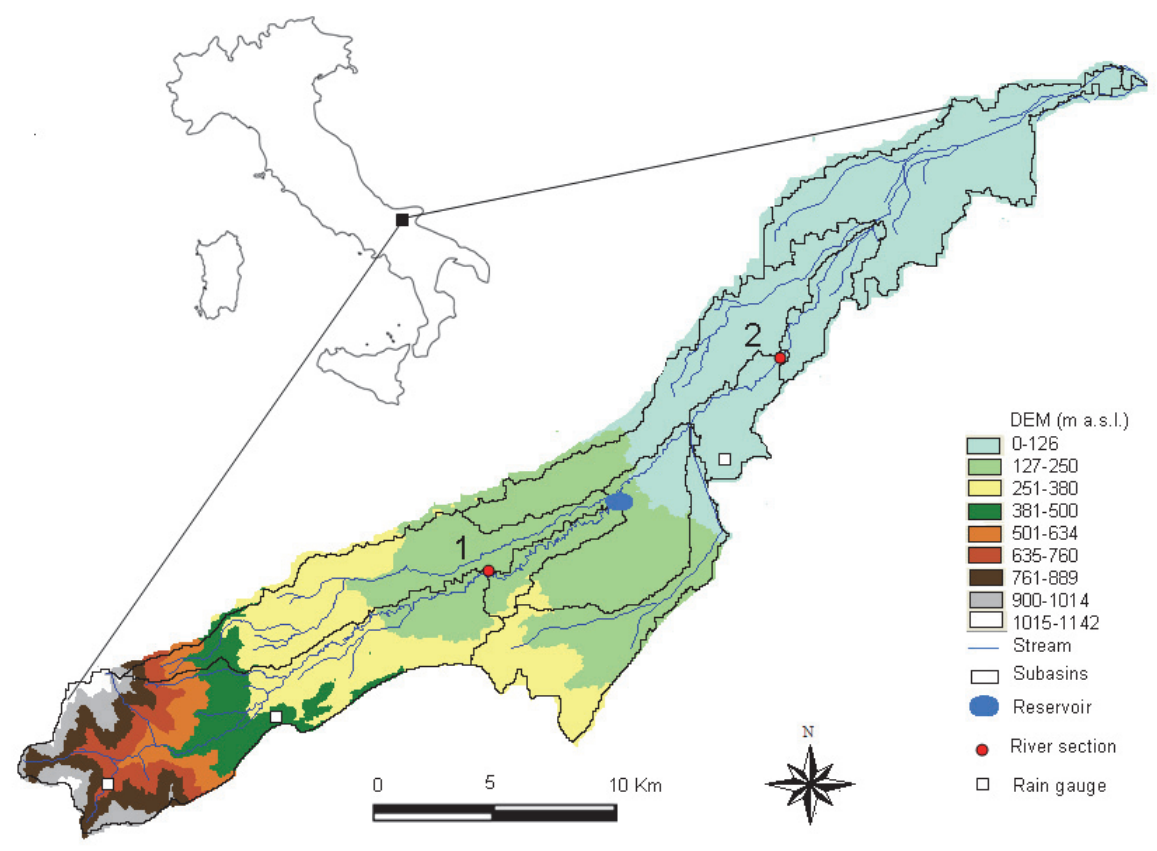

Fig. 1. Study area: Celone River basin. Numbers $(1,2)$ denote both the river sections where streamflow gauging stations are installed and the investigated river segments. 
Point source discharges from waste water treatment plants (WWTPs), water abstractions from the river and groundwater, and a reservoir are the main anthropogenic hydrological pressures. Data quantifying the water abstraction are not available. An irrigation board that operates in the plain area with a welldefined irrigation system provides water at a competitive price. In spite of this, water abstraction from surface water and groundwater is quite common, especially in the plain area of the basin. Volumes of waste water discharged by WWTPs are provided on a yearly basis. Significant land use changes, which could have induced an increase in impervious areas, had not been recorded in recent decades.

\section{MATERIAL AND METHODS \\ Indicators of hydrological alteration}

In 2011, the Italian Decree 260/2010 (D.M. Ambiente n. 260, 2010; Annex 1; Tab. 4.1.2/a) fixed the technical criteria to classify the hydrological and morphological conditions of a river needed to support a functioning ecosystem. The Decree proposes an index, the so called Indice di Alterazione del Regime Idrologico (IARI), to evaluate the deviation of the current hydrological regime from its natural condition and it defines a classification of the regime alterations. The above mentioned Decree also fixes a threshold value of the IARI index which identifies a critical ${ }^{3}$ hydrological status for which further analysis is needed. In the latter case, the methodology has to be defined case by case on the basis of hydrological pressures which can modify all the components of a regime or only a few (ISPRA, 2011).

ISPRA (2011) suggested to use the "Indicators of Hydrological Alteration (IHA)" methodology of Richter et al. (1996) which uses 32 indices to describe hydrological regime and its deviation from un-impacted condition (The Nature Conservancy, 2009). In alternative, the efforts can be direct to the values of specific indices selected on the basis of anthropogenic pressures (Olden and Poff, 2003). For instance, as it is expected that summer water abstractions will impact monthly streamflow and extreme low-flow components of the hydrological regime, we can select and analyze the metrics describing these flow regime components only (Black et al., 2005).

The method presented in this paper includes two stages. The first is aimed at identification of the water bodies in a critical hydrological status, as suggested by the Italian Decree $260 / 2010$. The second analyses in detail the effects of pressures on the hydrological regime components.

\section{Hydrological Regime Alteration Index (IARI)}

The first stage comprises the following steps:

1. Hydrological pressures analysis: information and data about the river network and catchment are collected in order to evaluate pressures and their potential impacts on the waters.

2. Identification of the relevant river sections, following the criteria of the WFD (CIS, 2003b).

3. Identification of river segments whose hydrological regime is being significantly influenced by anthropogenic activities.

4. For the impacted river segments, evaluation of the IARI index following the procedure described by the Istituto Superiore per la Protezione e la Ricerca Ambientale (ISPRA, 2011). Depending on the available streamflow data, quality and consistency, the IARI index is calculated, by comparing the daily or monthly discharges actually flowing through the cross section and the corresponding natural river discharges. In particular, as in this case, since many of the major changes to the hydrological regime pre-date the start of the streamflow records, natural stream discharge was evaluated using a hydrological model, while the impacted hydrological condition is evaluated by using measured data. The IARI index is evaluated using the following equation:

$$
I A R I=\frac{1}{12} P_{i, k}
$$

with $P_{i, k}=0$ if $Q N_{0.25, i} \leq Q_{i, k} \leq Q N_{0.75, i}$

or $P_{i, k}=\min \left(\left|\frac{Q_{i, k}-Q N_{0.25, i}}{Q N_{0.75, i}-Q N_{0.25, i}}\right|,\left|\frac{Q_{i, k}-Q N_{0.75, i}}{Q N_{0.75, i}-Q N_{0.25, i}}\right|\right)$ if

$Q_{i, k}<Q N_{0.25, i}$ or $Q_{i, k}>Q N_{0.75, i}$

where: $Q_{i, k}$ is the monthly median value of the measured streamflow over the current period (at least five years), $Q N_{0.25, i}$ and $Q N_{0.75, i}$ are, respectively, the natural streamflows that correspond to the $25^{\text {th }}$ and $75^{\text {th }}$ percentiles of the monthly median values recorded over a period of 20 years or more.

The Italian Decree 260/2010 fixed three hydrological status classes: High $(0 \leq \mathrm{IARI} \leq 0.05)$; Good $(0.05 \leq \mathrm{IARI} \leq 0.15)$; and Critical (IARI $>0.15$ ). If the IARI index reaches values higher than 0.15 , the hydrological status is critical and further analysis (Stage 2) is needed.

In the calculations of the IARI index we have to take into account that when the streamflow data sets used for the calculations of the metrics in natural and impacted conditions cover different periods, it is necessary to analyze the rainfall regime recorded in the two periods. In fact, differences in rainfall amount recorded in the two periods could determine an overestimation or under-estimation of impacts.

\section{MIRAGE protocol to quantify hydrological status}

The second stage suggested by ISPRA (2011) aims to quantify the alterations in the hydrological regime. As in Celone River basin the anthropogenic pressures will cause changes in the magnitude of low-flow and duration of the zero-flow period, we analyzed the metrics which describe these components of regime. In particular, we applied the MIRAGE protocol (De Girolamo et al., 2014; Gallart et al., 2012; Prat et al., 2014), which uses two metrics based on the statistics of the zero-flow period. The indices described below are evaluated both in unimpacted (natural) and impacted (actual) conditions and are used as coordinates in a plot, so that their position provides a river regime classification of the river bodies pre- and postimpact and a quantification of the deviation. The metrics are: the relative annual number of months with flow $\left(M_{f}\right)$ and the six-month dry season predictability $\left(S d_{6}\right)$ defined by Equation (2).

$S d_{6}=1-\left(\sum_{1}^{6} F d_{i} / \sum_{1}^{6} F d_{j}\right)$

where: $F d_{i}$ is the multi-annual frequency of the zero-flow months for the contiguous six wetter months per year and $F d_{j}$ is 
the multi-annual frequency of the zero-flow months for the remaining drier six months. The contiguous wet or dry sixmonths are the periods with fewer or more zero-flow frequencies, respectively. In the study area, the wetter sixmonth period is December to May, while the drier six-month period is June to November. If zero-flow months occur equally throughout the year over a long period, $S d_{6}$ assumes the value 0 ( $\sum_{1}^{6} F d_{i}=\sum_{1}^{6} F d_{j}$ in Eq. 2). This means that there is no clear predictability of streamflow processes. If zero-flow months occur in the same drier 6-month period every year, $S d_{6}$ takes the value $1\left(F d_{i}=0\right.$ in Eq. 2), which means that there is a high predictability. When the river is permanent, this metric cannot be calculated, we assume that $S d_{6}$ is 1 which means a fully predictability.

We selected these metrics, which are based only on the statistics of the zero-flow periods, directly $\left(S d_{6}\right)$ or indirectly $\left(M_{f}\right)$, because the flow interruption is considered to be the most relevant feature controlling the aquatic fauna in a temporary stream (Prat et al., 2014). At the same time, their use offers two advantages: firstly, flow interruption is much easier to identify than flow values when inhabitants or technicians are to be interviewed in absence or paucity of data, and secondly, the zero flow condition is also easier to model than a range of flow. We used simulated streamflow values and measured streamflow data to evaluate the metrics for the un-impacted and impacted conditions, respectively.

\section{Modelling approach to simulate natural streamflow}

We used the SWAT model (Arnold et al., 1998; Srinivasan et al., 1998), version SWAT2005 with ArcGIS interface (Winchell et al., 2007), to simulate streamflow values in two river sections on the River Celone. The SWAT model, which is widely used in watershed management, is able to simulate hydrological processes and water quality for both natural and impacted conditions in agricultural basins (Kiesel et al., 2013). The model was developed for ungauged basins, it was applied with good results in Mediterranean basins where flow data were scarce (De Girolamo and Lo Porto, 2012) and in semi-arid basins with a limited data set (Abouabdillah et al., 2014). However, uncertainty in model predictions have to be accurately analyzed (Abbaspour et al., 2007; van Griensven et al., 2002).

In the first SWAT simulation, the anthropogenic impacts were included and after the calibration and validation a new simulation without hydrological pressures was undertaken in order to predict the natural streamflow. The inputs used in the model and their relative sources are summarized in Table 1. In this study, survey campaigns and interviews with farmers and citizens were fundamental in order to establish reaches with intermittent characters and impacts (i.e. water abstractions).

Based on the availability of climatic data (daily rainfall and temperature), the model was run on a daily time-step from January 1990 to December 2009, a time period over which only a few years of measured flow data were available. In fact, at the gauging station 1 daily data were recorded from 1965 to 1995 ; while at the gauging station 2 streamflow was measured from 1965 to 1994 on daily time scale and from 2000 to 2010 on monthly time scale.

The study area was divided into nine sub-basins. Taking into account the fact that daily wind speed and daily relative humidity were not available, the Hargreaves and Samani (1985) method was chosen to evaluate evapotranspiration. This method requires only daily maximum and minimum air temperature data and is able to produce realistic results for semiarid areas. The Soil Conservation Service Curve Number method (SCSCN) (USDA-Soil Conservation Service, 1972) was selected to calculate surface runoff, since only daily rainfall values were available for the study area. Prior to calibration, the sensitivity analysis (SA) developed by van Griensven et al. (2002) was carried out for 27 parameters to assess the most sensitive hydrological parameters that can influence river flow. That analysis was performed with a module which is incorporated in the SWAT model. Among the most sensitive parameters are soil depth $(\mathrm{z}[\mathrm{mm}])$, curve number $(\mathrm{CN})$, threshold depth of water in the shallow aquifer for return flow (GW_QMIN [mm]), antecedent soil water content ( $\mathrm{SOL}$ AWC $\left[\mathrm{mm} \mathrm{H}_{2} \mathrm{O} / \mathrm{mm}\right.$ soil] $)$, soil evaporation compensation factor (ESCO), and surface runoff lag time [days]. An initial manual calibration was undertaken working with the above mentioned parameters influencing surface flow and base flow in order to have a smaller range of parameters than the initial range. After this step, the Sequential Uncertainty Fitting version 2 (SUFI 2) procedure (Abbaspour, 2011), included in the SWAT-CUP software (http://www.neprashtechnology.ca/), was applied to carry out the uncertainty analysis. In SUFI 2, uncertainty is the discrepancy between measured and simulated streamflow. It reflects all sources of uncertainties (conceptual model, forcing inputs i.e. rainfall, parameters and measured data). For a comprehensive description of the algorithm, refer to Abbaspour et al. (2007).

Table 1. SWAT model input data.

\begin{tabular}{|c|c|c|c|}
\hline Variable & Origin & Scale & Method \\
\hline Precipitation & $\begin{array}{l}\text { Civil Protection Service } \\
\text { Apulia Reg. Agency }\end{array}$ & Daily value (on basin scale) & $\begin{array}{l}3 \text { rainfall stations } \\
(1990-2009)\end{array}$ \\
\hline Temperature & $\begin{array}{l}\text { Civil Protection Service } \\
\text { Apulia Reg. Agency }\end{array}$ & Daily value (on basin scale) & $\begin{array}{l}2 \text { temperature stations } \\
(1990-2009)\end{array}$ \\
\hline Land use map & $\begin{array}{l}\text { Corine Land Cover } 2000 \text { EU } \\
\text { Project }\end{array}$ & $\begin{array}{l}\text { ArcInfo format } \\
\text { (scale 1:100000) }\end{array}$ & $\begin{array}{l}\text { Minimum area digitalized } \\
25 \text { ha }\end{array}$ \\
\hline Soil map & $\begin{array}{l}\text { ACLA } 2 \text { - FEOGA EU } \\
\text { Project }\end{array}$ & $\begin{array}{l}\text { ArcInfo format } \\
\text { (scale 1:100000) }\end{array}$ & 9 soil profiles \\
\hline $\begin{array}{l}\text { Management } \\
\text { Practices }\end{array}$ & $\begin{array}{l}\text { Consorzio per la Bonifica } \\
\text { della Capitanata }\end{array}$ & & $\begin{array}{l}\text { Irrigation amount, tillage } \\
\text { oper., fertilizers appl. }\end{array}$ \\
\hline $\begin{array}{l}\text { Digital Elev. Model } \\
\text { Waste Water }\end{array}$ & Apulia River Basin Authority & Arc Info grid format $(40 \mathrm{x} 40 \mathrm{~m})$ & \\
\hline $\begin{array}{l}\text { Treatment Plants } \\
\text { discharges }\end{array}$ & Ecological Police (FG) & Average daily values & Daily discharges $\left(\mathrm{m}^{3} / \mathrm{s}\right)$ \\
\hline
\end{tabular}




\section{RESULTS AND DISCUSSION}

As mentioned above, point source discharges from waste water treatment plants (WWTPs), water abstractions from the river and groundwater, and a reservoir are the main hydrological pressures in the Celone river basin. In the present study, we used a river network fragmentation based on the "water bodies" defined by the River Basin Authority of Apulia region (D.M. Ambiente n. 131, 2008). This is because the "water body"4 is the coherent sub-unit in the river basin to which the environmental objectives of the WFD must apply. The main purpose of identifying "water bodies" is to enable the status to be accurately described and compared to environmental objectives (WFD, Art. 4). As suggested in the Guidance Document No. 2 (CIS, 2003b), geographical and hydromorphological features in addition to considerations regarding pressures and impacts are the main criteria for delineating the surface water bodies.

Here, two river segments are analysed: the first is representative of the upper river basin and the second is typical of the plain area of the basin (in Figure 1, river segment 1 and 2, respectively). Streamflow values used to calculate the metrics are measured or simulated in the river section 1 and 2, also called in the text streamflow gauge 1 and 2 (Figure 1). Nevertheless, we have to bear in mind that temporary rivers are characterized by high longitudinal variation in river flow in addition to the temporal variation (Larned et al., 2010). During the dry season, flow may appear and disappear longitudinally depending on the substrate of the river bed, and on the geological formation that regulates the bidirectional surface-aquifer exchanges. Flow regime characterization based on hydrological indices is site specific; this means that many index values computed for one site may vary upstream and downstream in response to the longitudinal changes in streamflow.

\section{Model performance}

The model was calibrated over the period 1990-1992 at gauge 1 and from 1990 to 1991 at gauge 2 . The performance of the model simulations was evaluated by using Nash and Sutcliffe efficiency (NSE) (Nash and Sutcliffe, 1970) and the correlation coefficient $\left(\mathrm{R}^{2}\right)$. Both of these statistics are included in the performance evaluation methods and criteria suggested by the developers (Arnold et al., 2012). For the calibration period, the NSE value at Gauge 1 (Figure 2) was 0.61 and at Gauge 2 was 0.51 ; the $\mathrm{R}^{2}$ values were 0.88 and 0.83 , respectively. For the validation period (1994-1995), at gauge 1 the NSE was 0.41 and $R^{2}$ was 0.77 , while at gauge $2(1994)$ the NSE was 0.83 and
$\mathrm{R}^{2}$ was 0.93 (Figure 3 ). The correlation coefficient $\mathrm{R}^{2}$ ranges from 0 to 1 , with higher values indicating less error variance, and typically values greater than 0.5 are considered acceptable (Legates and McCabe, 1999). NSE is very commonly used, Sevat and Dezetter (1991) found NSE to be the best objective function for reflecting the overall fit of a hydrograph. NSE ranges between $-\infty$ and 1.0, with NSE $=1$ being the optimal value. In their review of published literature, Moriasi et al. (2012) defined "satisfactory" the values of NSE $>0.50$ for a monthly time step run simulation. Typically, model performance is poorer for shorter time step (daily) than for longer time steps (i. e. monthly) (Engel et al., 2007). For all of that and because of the fact that streamflow simulation in temporary rivers is more challenging that in perennial rivers, we consider the model performance acceptable.

The parameters, their range and the calibrated values are summarized in Table 2.

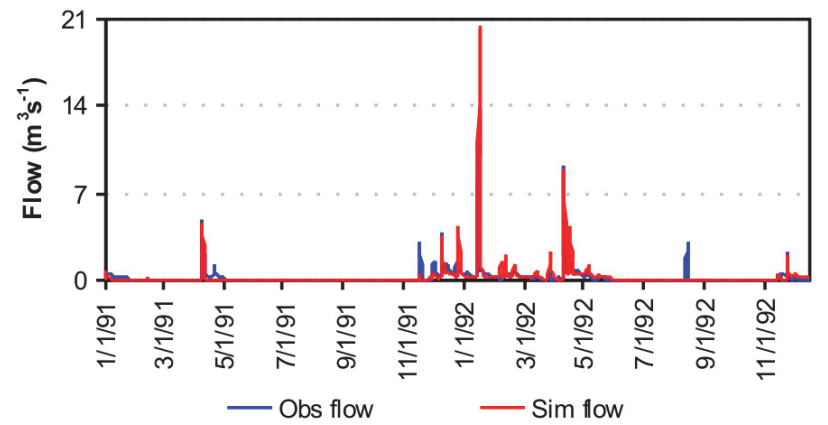

Fig. 2. Measured and simulated streamflow at gauge 1. Calibration (1991-1992).

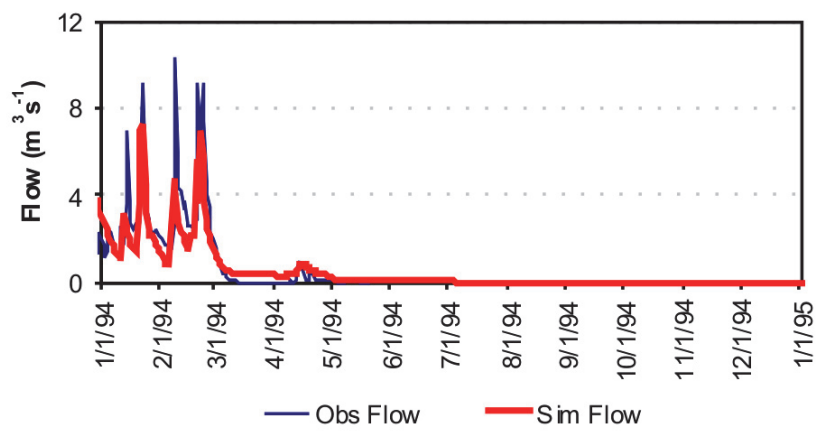

Fig. 3. Measured and simulated streamflow at gauge 2. Validation (1994).

Table 2. SWAT model parameters, their range and calibrated values.

\begin{tabular}{|c|c|c|c|c|}
\hline Parameter & Rank & Description & Calibrated values & Range \\
\hline Sol_Z & 1 & Soil depth $[\mathrm{mm}]$ & $150-500^{\mathrm{a}}$ & $0-3500$ \\
\hline $\mathrm{CN}^{-}$ & 2 & SCS Curve number & $54-88^{\mathrm{a}}$ & $35-98$ \\
\hline GWQMN & 3 & $\begin{array}{l}\text { Threshold depth of water in the shallow aquifer } \\
\text { required for return flow to occur [mm] }\end{array}$ & $0-10^{\mathrm{b}}$ & $0-5000$ \\
\hline Canmx & 4 & Maximum canopy storage $[\mathrm{mm}]$ & $3-7^{\mathrm{a}}$ & $0-100$ \\
\hline SOL_AWC & 5 & Available water capacity $\left[\mathrm{mm} \mathrm{H}_{2} \mathrm{O} / \mathrm{mm}\right.$ soil $]$ & $0.08-0.16^{\mathrm{a}}$ & $0.00-1.00$ \\
\hline ESCO & 6 & Soil Evaporation compensation factor & 0.35 & $0-1$ \\
\hline BLAI & 7 & Maximum potential leaf area Index $\left[\mathrm{m}^{2} / \mathrm{m}^{2}\right]$ & $1.25-5$ & $0.50-10$ \\
\hline SURLAG & 8 & Surface runoff lag coefficient [days] & 7 & $0-10$ \\
\hline GWREVAP & 9 & Revap coefficient & $0.08-0.16^{\mathrm{b}}$ & $0.02-0.20$ \\
\hline ALFA_BF & 10 & Baseflow factor [days] & $0.37-0.9^{\mathrm{b}}$ & $0.00-1.00$ \\
\hline
\end{tabular}

\footnotetext{
${ }^{a}$ value varies according to input data (soil, land use)

b value was adapted in subbasins depending on their location: Monti Dauni (upstream stations 1), Tavoliere (downstream 1).
} 
It is well known that watershed models suffer from uncertainty in predictions due to model structure, input data and parameters (Refsgaard et al., 2007). In the present work, we applied the SUFI 2 procedure to undertake the uncertainty analysis. Figure 4 represents the observed streamflow and the "best simulation" for un-impacted conditions and the $95 \%$ prediction uncertainty (95PPU) for gauge 1. As the graph shows, the uncertainty interval is large during the dry period. These results confirmed the studies of Kirkby et al. (2011) who pointed out that a discrepancy between measured and simulated flow is especially recorded in temporary rivers where extreme lowflow conditions tend to be overestimated by most hydrological models.

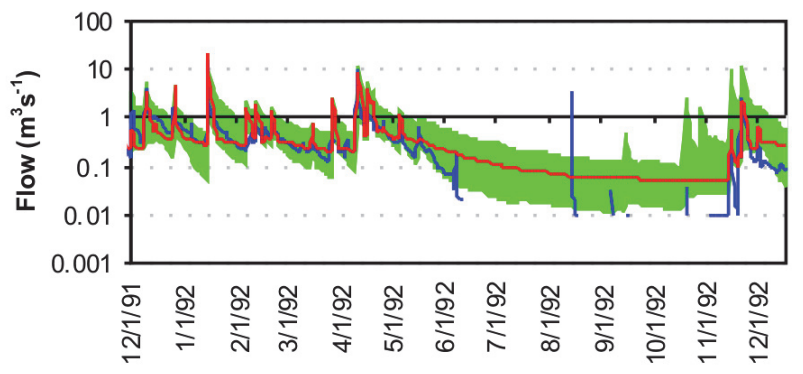

95PPU - Obs flow Sim flow

Fig. 4. Comparison of the hydrograph and uncertainty prediction at gauge 1. Obs flow represents measured discharge in impacted conditions and Sim flow represents the calibrated simulation in natural conditions. The shaded (green) interval is the $95 \%$ uncertainty predictions $(\mathrm{P}$-factor $=0.41$; and $\mathrm{R}$-factor $=0.20$ ).

In the present work, the "no-flow" condition is a key point in the metrics calculations; thus, it is important to understand whether or not the extreme low-flow conditions predicted by the SWAT model in a river section are realistic. If predicted extreme low flow in the "best simulation" is not zero in those reaches that are recognized as temporary streams, a correction of flow series is needed before calculating the metrics. The simulated streamflow value that corresponds to actual no-flow in a reach is the "zero-flow" threshold. This value is specific for each river section depending on the local conditions (i.e. hydraulic conductivity, river bed permeability, geology), in addition to the intrinsic limits of the hydrological model used for the simulations. Therefore, the "zero-flow" values should be determined comparing contemporaneous simulated and measured streamflow data. Generally, this is not an easy task since measured streamflows in natural conditions are unavailable. In order to identify this value, we selected one of the driest summers recorded in the past (1990) during which the river network was dry all over; we verified this condition through interviews with farmers, and for each river section we assumed the extreme low-flow value simulated by the model in that period as the zero-flow threshold. The values are 0.055 and $0.065 \mathrm{~m}^{3} \mathrm{~s}^{-1}$ for gauge 1 and gauge 2, respectively.

\section{IARI index evaluation}

The IARI index was evaluated in River Section 1 comparing the actual monthly median streamflow, evaluated from 1972 to 1996 (including 20 years of data) with the natural streamflow that corresponds to the $25^{\text {th }}$ and $75^{\text {th }}$ percentiles of the monthly median values simulated over a period of 20 years. Figure 5 represents the natural streamflow percentiles $25^{\text {th }}-75^{\text {th }}$ and the median actual monthly streamflow. From June to October, actual values are less than the $25^{\text {th }}$ percentile. The IARI index is $0.52(>0.15)$, denoting a critical hydrological status.

At gauge 2, the IARI index was evaluated comparing median measured monthly streamflow from 2000 to 2010 (covering 9 years of data) versus natural monthly streamflow (percentiles $\left.25^{\text {th }}-75^{\text {th }}\right)$ simulated over the period $1990-2009$. Figure 6 shows actual monthly median streamflow and natural streamflow $\left(25^{\text {th }}\right.$ and $75^{\text {th }}$ percentiles). The median measured streamflow in actual conditions (impacted) is lower than the $25^{\text {th }}$ percentile of the natural streamflow from January to December. The IARI index is $0.39(>0.15)$, also indicating that, in this river section, the hydrological status is critical. If we take into account that from 1990 to 2009 , the time period over which the un-impacted conditions were simulated, a contraction of the mean annual precipitation was recorded in all gauging stations varying from 5 to $11 \%$ compared to the recorded rainfall from 1972 to 1996 , when the actual conditions were evaluated, we could expect that the median measured streamflow (impacted) would be included in the interval $25^{\text {th }}$ and $75^{\text {th }}$ percentiles or even higher. As we found that impacted streamflow is lower than the $25^{\text {th }}$ percentiles, it is evident that natural streamflow has been altered by human activities (Figures 5 and 6).

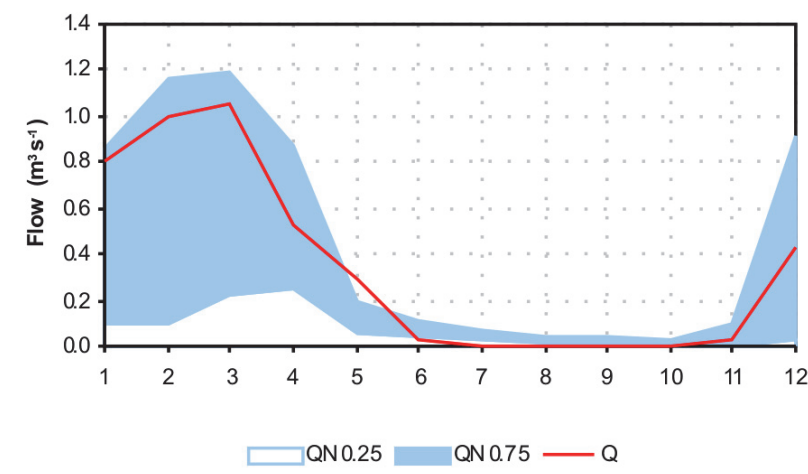

Fig. 5. Natural streamflow ( $25^{\text {th }}$ and $75^{\text {th }}$ percentiles) and actual monthly median streamflow (Q) at River Section 1.

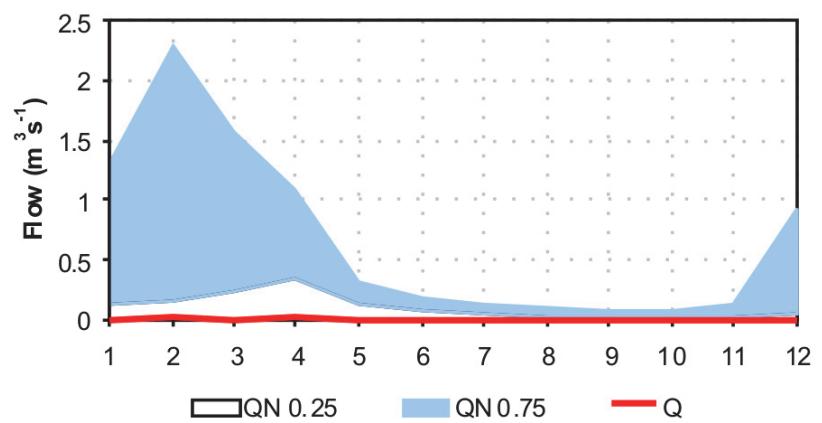

Fig. 6. Natural streamflow ( $25^{\text {th }}$ and $75^{\text {th }}$ percentiles) and actual monthly median streamflow (Q) at River Section 2.

\section{MIRAGE protocol to quantify hydrological status}

The IARI index denoted a critical hydrological status, which must be further analysed to identify which components of the regime are altered and to quantify their alteration. Poff et al. (2010) suggested formulating some hypotheses based on expert knowledge describing expected ecological changes derived from specific hydrological alterations and to investigate a limited set of hydrological indices. Following these suggestions, we focused Stage 2 of the method on changes occurring in flow permanence $\left(M_{f}\right)$ and dry season predictability $\left(S d_{6}\right)$. In fact, in 
the study area, it is highly plausible that the contraction of flow permanence recorded in the river segments will lead to a loss in diversity of invertebrate species and to a reduction of suitable aquatic habitats (Bonada et al., 2007). The two metrics defined previously, $M_{f}$ and $S d_{6}$, were evaluated for each river section in natural and un-impacted conditions. The metrics were used as coordinates in a plot, Figure 7, which provides a classification of the river types: moving from the upper-right corner to the lower-left, the intermittence of the river and, consequently, the influence of the regime on biological habitats increase.

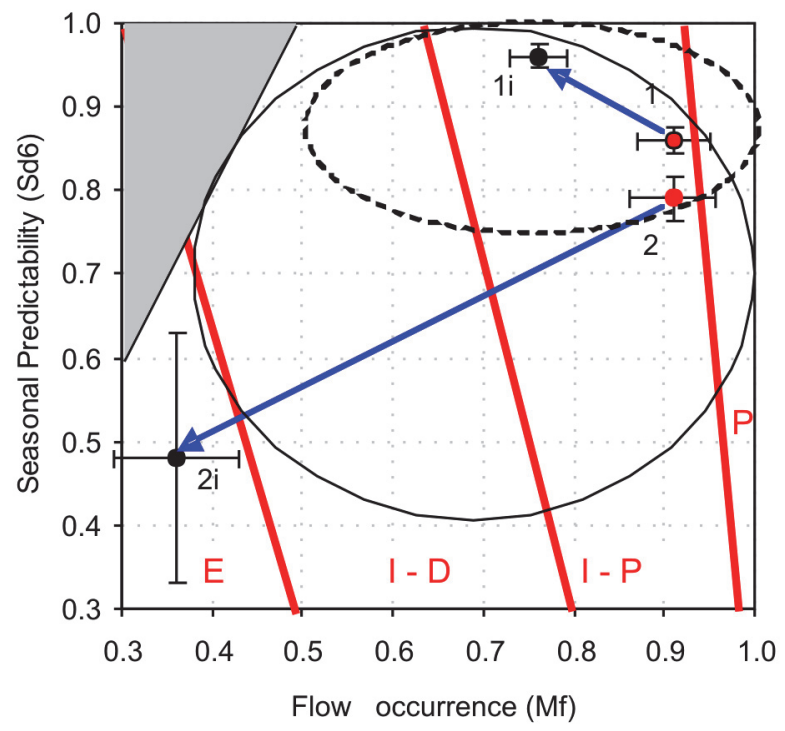

Fig. 7. Plot of inter-annual $S d_{6}$ versus $M_{f}$ metrics in impacted (black points: $1 \mathrm{i} ; 2 \mathrm{i}$ ) and natural (red points $1 ; 2$ ) conditions. Error bars show the standard error. The grey triangle shows the area where the metrics are incompatible. The red lines show an approximate separation between the regime types - permanent $(\mathrm{P})$, intermittent pools (I-P), intermittent dry (I-D) and ephemeral (S) streams; for details see the text below. The ellipses represent the natural range of variability for the two metrics; dotted and continuous ellipses represent river segment 1 and 2, respectively.

In the plot, the grey triangle identifies an area where the metric values are incompatible (i.e. if $M_{f}$ takes the value $0.4, S d_{6}$ cannot assume values higher than 0.8, as a result of Equation 2). The red lines differentiate the river regimes and river types; they are fixed after analysing data recorded in several streams in the Mediterranean area (Gallart et al., 2012). In their work, Gallart et al. (2012) classify rivers on the basis of the control imposed on the biological communities by the absence of flow. In particular, streams are classified as permanent $(\mathrm{P})$, intermittent pools (I-P) if streamflow is discontinuous with only pools during dry season; intermittent dry (I-D) if streamflow is absent during dry season; and ephemeral (E) if flow permanence is episodic. The distance between the corresponding points in unimpacted and impacted conditions is an indicator of the hydrological regime alterations capturing a shift in flow permanence and dry season predictability. The points representing the river reaches in natural conditions ( 1 and 2 ) are located on the right in the graph. When we calculate the metrics by using measured data, which include the impacts (water abstractions and the reservoir), the points move from the right to the left (1i and 2i). In particular, the plot in Fig. 7 shows that River segment 1 remains an intermittent-pool stream after the impacts and River segment 2, which was classified as an intermittent-pool river in natural conditions, became ephemeral after the dam was built. In the plot, the ellipses identify the natural range of variability for the two hydrological metrics. Due to a high inter-annual variability of rainfall regime recorded in the basin, the metrics assumed different values for the 20 years used to represent the natural regime of the river.

In the present work, we do not evaluate the ecological response to hydrological alterations, as biological data were not available. Nevertheless, we can deduce some considerations from the metrics and their deviation from natural status. A wide literature in ecohydrology including studies that relate ecological aspects of ecosystem to one or more hydrological variables is available (Bunn and Arthington, 2002). However, few studies have been published which have quantified the ecological metrics changes in response to various degrees of flow alteration per se (Poff et al., 2010). This is because it requires that hydrological variables and their deviations from natural condition are evaluated in the same location of ecological samplings, what has rarely been done (Poff and Zimmerman, 2010). Generally, the hydrologists and biologists' activities are not really integrated. Therefore, hydrologists may not have a clear picture of which aspects of biology should be included in their studies while biologists perceive only some of the concepts behind hydrology. Currently, reliable models directly predicting ecological response to various types and degree of alterations are not available. This is the main goal of environmental flow science (Poff et al., 2010).

In River section 1 , the metrics $M_{f}$ and $S d_{6}$ in impacted conditions assume values included in the range of their natural variability (dotted ellipse in the plot); consequently we can reasonably presume that in the upstream river segment variation in terms of ecosystem processes, magnitudes of transport of nutrients and suspended sediment materials, which are dictated by the hydrological regime, are low.

In contrast, the ecological response in River section 2, due to hydrological alterations, could be relevant, as both metrics calculated in River section 2 after impact reach the values which are far from their natural variability interval (the point $2 \mathrm{i}$ is outside the ellipse in the plot). As a consequence of the drastic reduction in flow permanence, the entire river segment remained dry for a long time and the water content in the alluvial soil constituting the river bed became similar to the surrounding terrestrial soil. Consequently, a different ecosystem may characterize the stream whose river bed may be invaded by plants and only terrestrial fauna may exist. Data concerning flow released from the dam were available on monthly time scale only, while specific information on the dam water operation were not available. The River Basin Authority has not yet established a protocol for flow release. As a consequence, dam operators do not maintain adequate water flow to sustain river ecosystem downstream of the reservoir. In this context, the present work may constitute an interesting contribution to streamflow management providing both natural streamflow and hydrological alterations attributable to human influence, which are fundamental for estimating environmental flow downstream the reservoir. On the other hand, the plot in Fig. 7 provides information which is very important for interpreting the results of biological samplings. In fact, knowledge of the overall history and habitat characteristics present when biological samples are taken is a fundamental contribution in establishing the ecological status (ES) (Buffagni et al., 2010). Several researchers have highlighted the importance and the role of the flow type in macro-invertebrate community assemblages (Bonada et al., 2007; Munné and Prat, 2011). Buffagni et al. (2009) pointed out that an increase in lentic flow-related habitat may determine a decrease in the 
values of metrics used to evaluate ES. Thus, if these conditions are due to a natural variability in streamflow, a correction of ES assessment systems is needed in order to avoid an underestimation of the ecological quality.

\section{CONCLUSIONS}

Water resources managers who are in charge of protecting and restoring river ecosystems need quantitative tools to evaluate the hydro-morphological alterations of a river and the easy relationships linking hydrological alterations to ecological responses. Due to the limited availability of streamflow data, especially in natural conditions, the assessment of hydrological alterations attributable to human influence is not easy to determine in Mediterranean semi-arid basins. Despite these difficulties, the hydrological alteration of a water body needs to be evaluated in order to achieve the final objective of the WFD, and currently it constitutes a challenge for eco-hydrologists who have to define a methodology to evaluate hydrological alterations of a water body and the consequent ecological response.

In this paper, a first attempt to define a method for assessing hydrological alterations in temporary rivers was presented. The assessment of human-induced alterations in river flow regimes in the River Celone has been carried out based on a comparison of the simulated long-term river discharge (1990-2009) under natural condition and the anthropogenic altered conditions including impacts (water abstractions, point sources discharges and a reservoir).

The results show minor alterations in the upstream river segment, where changes in regime are limited. The river segment preserves its original hydrological regime classification. It remains an intermittent-pool river. The most important anthropogenic pressures which influence hydrological regime are water abstractions from surface water and point source discharges (WWTPs), so that the two amounts cancel each other out. In contrast, a very significant alteration to the natural flow regime was evaluated in the river segment in the plain area of the basin, where the effects of the reservoir appear to be the dominant cause of regime changes. The alterations refer to the monthly average river discharge, the permanence of flow and the six-month dry season predictability. Under the current conditions, each of these regime components is very far from its natural variability.

All these types of alteration are known to have an impact on the ecosystems in temporary rivers. Nevertheless, for an improved assessment of flow alteration impacts on ES, it is necessary to analyse the ecological response. Hence, further studies are needed including consideration of the impacts on specific aquatic species and of local knowledge on habitat degradation in temporary rivers. Such integrated ecohydrological study will give a contribution in establish environmental flow requirements and in regulating reservoir operations in the Celone river basin. The method presented here had to rely on simulated streamflow for undisturbed regime. Future research could also test the method in rivers where measured undisturbed data are available. The approach we proposed in the present paper may play a key role in the process of implementation of the Water Framework Directive, especially in view of the review and update of the first River Basin Management Plan in 2015 (according to the WFD timetable art. 13, 14, 15).

Acknowledgements. This study is a part of the EU "MIRAGE" (Mediterranean Intermittent River ManAGEment contract $\mathrm{n}^{\circ}$ $211735,7^{\text {th }}$ EU Framework Programme 2007-2011) which aims to provide specific key knowledge for a better assessment of ecological integrity (or ecological status, in the words of the European Water Framework Directive) in temporary Mediterranean streams. The authors gratefully acknowledge G. Amoruso from the Apulia Civil Protection Service and G. Niro from Consorzio per la Bonifica della Capitanata for providing data. The authors are indebted to A. Calabrese who collaborate in field activities. We are grateful to N. Prat for sharing constructive discussions.

\section{REFERENCES}

Abbaspour, K.C., Yang, J., Maximov, I., Siber, R., Bogner, K., Mieleitner, J., Zobrist, J., Srinivasan, R., 2007. Spatiallydistributed modelling of hydrology and water quality in the prealpine/alpine Thur watershed using SWAT. Journal of Hydrology, 333, 413-430.

Abbaspour, K.C., 2011. SWAT-CUP4: SWAT Calibration and Uncertainty Programs - A User Manual. Eawag 2011, Dübendorf, Switzerland.

Abouabdillah, A., White, M., Arnold, J.G., De Girolamo, A.M., Oueslati, O., Maataoui, A., Lo Porto, A., 2014. Evaluation of soil and water conservation measures in a semi-arid river basin in Tunisia using SWAT. Soil Use and Management, doi: 10.1111/sum. 12146

Arnold, J.G., Srinivasan, R., Muttiah, R.S., Williams, J.R., 1998. Large Area Hydrologic Modeling and Assessment Part I: Model Development. J. American Water Resour. Assoc., 34, 1, 73-89.

Arnold, J.G., Moriasi, D.N., Gassman, P.W., Abbaspour, K.C., White, M.J., Srinivasan, R., Santhi, C., Harmel, R.D., van Griensven, A., Van Liew, M.W., Kannan, N., Jha, M.K., 2012. SWAT: Model use, calibration, and validation. Transaction of the ASABE, 55, 4, 1494-1508.

Black, A.R., Rowan, J.S., Duck, R.W., Bragg, O.M., Clelland, B.E., 2005. DHRAM: a method for classifying river flow regime alterations for the EC Water Framework Directive. Aquatic Conserv.: Mar. Freshw. Ecosyst., 15, 427-446.

Bonada, N., Rieradevall, M., Prat, N., 2007. Macroinvertebrate community structure and biological traits related to flow permanence in Mediterranean river network. Hydrobiologia, 589, 91-106.

Buffagni, A., Armanini, D.G., Erba, S., 2009. Does lentic-lotic character of rivers affect invertebrate metrics used in the assessment of ecological quality? J. Limnol., 68, 95-109.

Buffagni, A., Erba, S., Armanini, D.G., 2010. The lentic-lotic character of Mediterranean rivers and its importance to aquatic invertebrate communities. Aquat. Sci., 72, 45-60.

Bunn, S.E., Arthington, A.H., 2002. Basic Principles and Ecological Consequences of Altered Flow Regimes for Aquatic Biodiversity. Environmental Management, 30, 4, 492-507.

CIS, 2003a. River and lakes typology, reference conditions and classification systems, Common Implementation Strategy for the Water Framework Directive (2000/60/EC), Guidance document No 10, European Commission, 86 pp. Available at: http://circa.europa.eu

CIS, 2003b. Identification of Water Bodies, Common Implementation Strategy for the Water Framework Directive (2000/60/EC), Guidance document No 2, European Commission: 23 pp. Available at: http://circa.europa.eu.

De Girolamo, A.M., Lo Porto, A., 2012. Land use scenario development as a tool for watershed management within the Rio Mannu Basin. Land Use Policy, 29, 691-701.

De Girolamo, A.M., Lo Porto, A., Pappagallo, G., Tzoraki, O., Gallart, F., 2014. The hydrological status concept: Applica- 
tion at a temporary river (Candelaro, Italy). River Research and Applications, doi: 10.1002/rra.2786

DM Ambiente n. 260, 2010. Criteri tecnici per la classificazione dello stato dei corpi idrici superficiali - Modifica norme tecniche Dlgs 152/2006. [Technical criteria for classifying water quality status of surface water bodies]. So alla GU n. 30, 7 febbraio 2011. (In Italian.)

DM Ambiente n. 131, 2008. Criteri tecnici per la caratterizzazione dei corpi idrici - Attuazione articolo 75, Dlgs 152/2006. [Technical criteria for characterizing water bodies]. So alla GU n. 187, 11 agosto 2008. (In Italian.)

EC, 2000. Directive 2000/60/EC of the European Parliament and the Council Directive establishing a framework for Community action in the field of water policy. Official Journal of the European Communities, Brussels, 22/12/2000.

Engel, B., Storm, D., White, M., Arnold, J., Arabi, M., 2007. A hydrologic/water quality model application protocol. J. American Water Resour. Assoc., 43, 5, 1223-1236.

Fernández Yuste, J.A., Martínez Santa-María, C., Magdaleno, F., 2012. Application of hydrologic alterations in the designation of heavily modified water bodies in Spain. Environmental Science \& Policy, 16, 31-43.

Gallart, F., Prat, N., García-Roger, E.M., Latron, J., Rieradevall, M., Llorens, P., Barberá, G.G., Brito, D., De Girolamo, A.M., Lo Porto, A., Buffagni, A., Erba, S. Neves, R., Nikolaidis, N.P., Perrin, J.L., Querner, E.P., Quiñonero, J.M., Tournoud, M.G., Tzoraki, O., Skoukulidis, N., Gomez, R., Sanchez-Montoya, M., Froebrich, J., 2012. A novel approach to analysing the regimes of temporary streams in relation to their controls on the composition and structure of aquatic biota. Hydrol. Earth Syst. Sci., 16, 1-18.

Hargreaves, G.H., Samani, Z.A., 1985. Reference crop evapotranspiration from temperature. Applied Engineering in Agriculture, 1, 96-99.

Hering, D., Buffagni, A., Moog, O., Sandin, L., Sommerhäuser, M., Stubauer. I., Feld, C., Johnson, R., Pinto, P., Skoulikidis, N., Verdonschot, P., Zahrádková, S., 2003. The development of a system to assess the ecological quality of streams based on macroinvertebrates - design of the sampling programme within the AQEM project. Hydrobiologia, 88, 345-361.

Henriksen, J.A., Heasley, J., Kennen, J.G., Nieswand, S., 2006. Users' Manual for the Hydroecological Integrity Assessment Process Software (Including the New Jersey Assessment Tools). Open-File Report 2006-1093. U.S. Geological Survey, Fort Collins Science Center, Fort Collins, CO.

ISPRA, 2011. Istituto Superiore per la Protezione e la Ricerca Ambientale, Dipartimento Tutela delle Acque Interne e Marine, Servizio Monitoraggio e Idrologia delle Acque Interne, Settore Idrologia: Implementazione della Direttiva 2000/60/CE. [Water Framework Directive implementation. Analysis and assessment of hydromorphological aspects. Version 1.1]. Analisi e valutazione degli aspetti idromorfologici. Versione 1.1, Roma. Available at: www.sintai.sinanet.apat.it/view/index.faces. (In Italian.)

Kiesel, J., Schmalz, B., Brown, G.L. Fohrer N., 2013. Application of a hydrological-hydraulic modelling cascade in lowlands for investigating water and sediment fluxes in catchment, channel and reach. J. Hydrol. Hydromech., 61, 4, 334346.

Kirkby, M.J., Gallart, F., Kjeldsen, T.R., Irvine, B.J., Froebrich, J., Lo Porto, A., De Girolamo, A., the MIRAGE team, 2011. Classifying low flow hydrological regimes at a regional scale. Hydrol. Earth Syst. Sci., 15, 3741-3750.

Lake, P.S., 2007. Flow-generated disturbances and ecological responses: Floods and droughts. In: Wood, P.J., Hannah,
D.M., Sadler, J.P. (Eds.): Hydroecology and Ecohydrology: Past, Present and Future. John Wiley \& Sons, Chichester, UK, pp. 75-92.

Larned, S.T., Datry, T., Arscott, D.B., Tockner, K., 2010. Emerging concepts in temporary-river ecology. Freshwater Biology, 55, 717-738.

Legates, D.R., McCabe, G.J., 1999. Evaluating the use of "goodness of fit" measures in hydrologic and hydroclimatic model validation. Water Resources Research, 35, 233-241.

Martínez Santa-María, C., Fernández Yuste, J.A., 2008. IAHRIS Índices de Alteración Hidrológica en Ríos. Manual de Referencia Metodológica. Versión 1. [IAHRIS Indicators of Hydrologic Alteration in Rivers. Methodological Reference Manual. Version 1.1]. CEDEX (Centro de Estudios y Experimentaciòn De Obras Pùblicas) [Center for Studies and Experimentation of Public Works]. (In Spanish.)

Moriasi, D.N., Wilson, B.N., Douglas-Mankin, K.R., Arnold, J.G., Gowda, P.H., 2012. Hydrologic and water quality models: use, calibration, and validation. Transactions of the ASABE, 55, 4, 1241-1247.

Munné, A., Prat, N., 2011. Effects of Mediterranean climate annual variability on stream biological quality assessment using macroinvertebrate communities. Ecol. Ind., 11, 651662.

Nash, J.E., Sutcliffe, J.V., 1970. River flow forecasting through conceptual models. Journal of Hydrology, 10, 282-290.

Nikolaidis, N.P., Demetropoulou, L., Froebrich, J., Jacobs, C., Gallart, F., Prat, N., Lo Porto, A., Campana, C., Papadoulakis, V., Skoulikidis, N., Davy, T., Bidoglio, G., Bouraoui, F., Kirby, M., Tournoud, M.G., Polesello, S., Barberá, G.G., Cooper, D., Gomez, R., Sanchez-Montoya, M.M., Latron, J., De Girolamo, A.M., Perrin, J.L., 2013. Towards a sustainable management of Mediterranean river basins. Policy recommendations on management aspects of temporary river basins. Water Policy, 15, 830-849.

Olden, J.D., Poff, N.L., 2003. Redundancy and the choice of hydrologic indices for characterizing streamflow regimes. River Research and Applications, 19, 101-121.

Oueslati, O., De Girolamo, A.M., Abouabdillah, A., Lo Porto, A., 2010. Attempts to flow regime classification and characterisation in mediterranean streams using multivariate analysis. In: Proceeding of the International Workshop Advances in statistical hydrology, May 23-25, 2010, Taormina, Italy.

Poff, N.L., 1996. A hydrogeography of unregulated streams in the United States and an examination of scale-dependence in some hydrological descriptors. Freshwater Biology, 36, 7191.

Poff, N.L., Allan, J.D., Bain, M.B., Karr, J.R., Prestegaard, K.L., Richter, B.D., Sparks, R.E., Stromberg, J.C., 1997. The natural flow regime. Bioscience, 47, 769-784.

Poff, N.L., Zimmerman, J.K.H., 2010. Ecological responses to altered flow regimes: a literature review to inform the science and management of environmental flows. Freshwater Biology, 55, 194-205.

Poff, N.L., Richter, B., Arthington, A.H., Bunn, S.E., Naiman, R.J., Kendy, E., Acreman, M., Apse, C., Bledsoe, B.P., Freeman, M., Henriksen, J., Jacobson, R.B., Kennen, J., Merritt, D.M., O'Keeffe, J., Olden, J.D., Rogers, K., Tharme, R.E., Warner, A., 2010. The Ecological Limits of Hydrologic Alteration (ELOHA): a new framework for developing regional environmental flow standards. Freshwater Biology, $55,147-170$.

Prat, N., Gallart, F., Von Schiller, D., Polesello, S., GarcíaRoger, E.M., Latron, J., Rieradevall, M., Llorens, P., Barberá, G.G., Brito, D., De Girolamo, A.M., Dieter, D., Lo Por- 
to, A., Buffagni, A., Erba, S., Nikolaidis, N.P., Querner, E.P., Tournoud, M.G., Tzoraki, O., Skoukulidis, N., Gomez, R., Sanchez-Montoya, M., Tockner, K., Froebrich, J., 2014. The MIRAGE TOOLBOX: an integrated assessment tool for temporary streams. River Research and Applications, doi: 10.1002/rra.

Refsgaard, J.C., van der Sluijs, J.P., Højberg, A.L., Vanrolleghem, P.A., 2007. Uncertainty in the environmental modelling process - A framework and guidance. Environmental Modelling \& Software, 22, 1543-1556.

Richter, B.D., Baumgartner, J.V., Powell, J., Braun, D.P., 1996. A method for assessing hydrologic alteration within ecosystems, Conservation Biology, 10, 1163-1174.

Sevat, E., Dezetter, A., 1991. Selection of calibration objective functions in the context of rainfall-runoff modeling in a Sudanese Savannah area. Hydrol. Sci. J., 36, 4, 307-330.

Singh, V.P., Woolhiser, D.A., 2002. Mathematical modelling of watershed hydrology. Journal of Hydrologic Engineering, 7, 270-292.

Srinivasan, R., Ramanarayanan, T.S., Arnold, J.G., Bednarz, S.T., 1998. Large area hydrologic modelling and assessment Part II: Model application. J. American Water Resour. Assoc., 34, 1, 91-101.

The Nature Conservancy, 2009. Indicators of Hydrologic Alteration Version 7.1 User's Manual.

USDA-Soil Conservation Service, 1972. In: National Engineering Handbook, Hydrology Section 4, 4-10.

van Griensven, A., Francos, A., Bauwens, W., 2002. Sensitivity analysis and auto-calibration of an integral dynamic model for river water quality. Water Science and Technology, 45, 9, $325-332$.
Winchell, M., Srinivasan, R., Di Luzio, M., Arnold, J., 2007. ArcSWAT interface for SWAT 2005. User's Guide, Blackland Research Center, Texas Agricultural Experiment Station, Temple.

Zoppini, A., Amalfitano, S., Fazi, S. Puddu, A., 2010. Dynamics of a benthic microbial community in a riverine environment subject to hydrological fluctuations (Mulargia River, Italy). Hydrobiologia, 657, 1, 37-51.

\section{NOTES}

${ }^{1}$ Rivers with dry period all over the water body or only in part of it, recorded either every year or at least twice within five years (Italian Legislative Decree 131/2008).

${ }^{2}$ The data from the rain gauge closest to the centroid of each subwatershed were selected as the sole input for that particular subwatershed. Then the areal rainfall data were assumed to be homogeneous across each sub-watershed.

${ }^{3}$ The divergence of impacted hydrological regime from its natural status is high (IARI index $>0.15$ ) and it may have a substantial relevance to aquatic ecology.

${ }^{4}$ The Directive requires Member States to identify "water bodies" as part of the analysis of the characteristics of the river basin districts. The analysis must be reviewed and, where necessary, updated by 22 December 2013 and then every six years.

Received 7 November 2014 Accepted 19 March 2015 